\title{
The Relationship Between Performance Indicators and Readmission of Patients With Open Heart Surgery: A Case Study in Iran
}

\author{
Parvin Ebrahimi ${ }^{1}$, Mohammadali Taghi Nattaj Darzi Naghibii ${ }^{*}$, Soudabeh Vatankhah ${ }^{1}$, Ghassem \\ Faghanzadeh Ganji²
}

${ }^{1}$ Department of Health Services Management, School of Health Management and Information Sciences, Iran University of Medical Sciences, Tehran, Iran

${ }^{2}$ Cardiac Surgery Department, Rohani Hospital, Babol University of Medical Sciences, Babol, Iran

*Corresponding Author: Mohammadali Taghi Nattaj Darzi Naghibi, MSc Student in Health Services Management, Department of Health Services Management, School of Health Management and Information Sciences, Iran University of Medical Sciences, Tehran, Iran. Tel: +98-9196639616, Email: mohamadali_nataj@yahoo.com

Received January 30, 2019; Accepted May 26, 2019; Online Published June 15, 2019

\begin{abstract}
Background: Open heart surgery is a prevalent therapeutic intervention for cardiovascular diseases. Significant adverse effects occur after heart surgery, one of which is patient readmission to the hospital.

Objective: The present study aimed to determine the relationship between performance indicators and the readmission of patients with open heart surgery in a teaching hospital in Iran.

Methods: This study was performed using a cross-sectional and descriptive method with a retrospective approach. Data was collected on a data collection form. The statistical population of this study comprised all patients who underwent open heart surgery from mid-September 2015 to mid-September 2016 in a teaching hospital in the north of Iran $(n=849)$. Those patients readmitted to the hospital within 90 days after discharge, based on a review of patient records, were included in the study. Descriptive statistics and Spearman correlation coefficient were used for data analysis by SPSS 20.

Results: Among the patients who had open heart surgery in the selected hospital, $12.5 \%$ were readmitted within 90 days after discharge. The most important reasons for readmission in this study were infection in surgery place (25.8\%), pleural effusion $(18.7 \%)$, warfarin toxicity $(9.8 \%)$, and tamponade $(8.9 \%)$. There were inverse relationships between patient readmission and the two performance indicators of bed occupancy percentage $(r=-0.594, P=0.042)$ and bed turnover rate $(r=-0.664$, $P=0.018$ ). There were no statistically significant relationships between any of the other indicators (length of stay, mortality, and bed turnover interval) and readmission rate $(P>0.1)$.

Conclusion: Hospital authorities can use these results for bed management and targeting interventions to reduce costs and readmissions as a measure of hospital quality. However, further research into readmission factors in other hospitals is recommended.

Keywords: Patient Readmission, Cardiac Surgery, Hospitalization, Quality Indicators
\end{abstract}

\section{Background}

Cardiovascular diseases (CVDs) are main causes of loss of health throughout the world. In 2015, the global burden of CVD was estimated at 422.7 million cases and 17.92 million deaths ${ }^{1}$ CVD is a leading cause of death ${ }^{2}$ and is responsible for $30-50 \%$ of premature deaths. ${ }^{3}$ In Iran, CVD is the main reason of mortality and disabilities, accounting for $44 \%$ of all deaths. ${ }^{4}$ CVDs also have considerable health and economic consequences, including, an increased demand for healthcare which raises health costs, and reduced productivity in the workplace ${ }^{5}$ due to lack of work or poor staff performance, which ultimately leads to lower economic growth and deeper poverty and inequality. CVD is a major obstacle for human development. ${ }^{1}$

Many advances have been made in the treatment of CVDs, ${ }^{6}$ such as surgery, angioplasty, medications, etc, and have helped reduce mortality from heart disease in many countries. ${ }^{4}$ No doubt, surgery on the heart is one of the most important and vital surgeries, ${ }^{7}$ and an increasing number of cardiovascular patients undergo various heart surgeries. $^{8}$ A number of undesirable effects occur after cardiac surgery, including patient readmission. ${ }^{9}$ Patients undergoing cardiac surgery are at high risk for a severe post-operative infection which could have devastating

Copyright (C) 2019 The Author(s). This is an open-access article distributed under the terms of the Creative Commons Attribution License (http:// creativecommons.org/licenses/by/4.0), which permits unrestricted use, distribution, and reproduction in any medium, provided the original work is properly cited. 
clinical outcomes and which imposes high costs on both patients and the healthcare system ${ }^{10}$ as reflected by long hospital stays and more readmissions. ${ }^{11}$

In a new movement to decrease healthcare costs, much attention has been focused on the rate of readmission during the first 30 days after discharge from hospital. ${ }^{12}$ The rate of readmission 30 days after discharge is about $20 \%$ among all Medicare patients with an approximate cost of $\$ 17.4$ billion. ${ }^{13,14}$ Hospital readmission is common, undesirable, and usually used as a quality indicator of care in the United States and England. Moreover, it is linked to financial penalties. ${ }^{15,16}$ Decreasing readmission provides an exclusive opportunity for improving quality and for reducing costs, and it is considered a priority in quality improvement. ${ }^{17}$ Some studies have shown that most readmissions are preventable; reducing readmission rates is considered a factor for improving quality in the future. ${ }^{18}$

The need to decrease costs arising from early rehospitalization and increasing readmission within 30 days after discharge has attracted the attention of researchers and other authorities to find solutions for reducing potential and preventable hospital readmissions. ${ }^{19}$ Indicators, such as readmission rate, bed occupancy, ${ }^{20}$ mortality, and length of stay, are used to assess hospital performance and quality of care and are interrelated, which will affect the explanation of hospital outcomes, ${ }^{21,22}$ although in some studies, such relationships have not been supported..$^{21}$ A limited number of studies have investigated patient readmission after heart surgery. ${ }^{9}$

Investigating the correlation between hospital performance indicators and readmission rate after heart surgery can help decision makers and authorities in carrying out necessary interventions to manage hospital beds, planning suitable solutions for decreasing patient readmission, reducing costs arising from patient readmissions, and increasing the quality of patient care.

\section{Objective}

It is noteworthy that to date, only a limited number of studies have investigated patient readmission in northern Iran. Furthermore, the teaching hospital selected for this study is the largest hospital in the region; there is no other hospital west of said province that can accommodate cardiac surgery patients. It seems that there are cases of patients being readmitted to this hospital after open heart surgery. Therefore, the current study aimed to investigate the relationships between performance indicators and readmissions of patients who have had open heart surgery in the teaching hospital in order to recognize the causes associated with patient readmissions and reduce them.

\section{Methods}

This cross-sectional and descriptive study was conducted with a retrospective approach. The statistical population of the study comprised all patients who had undergone open heart surgery between mid-September 2015 and mid-September 2016 in a teaching hospital in northern
Iran $(n=849)$. Those patients readmitted to the hospital during the first 90 days after discharge from hospital were included in the study.

It was deemed likely that some patients who had undergone heart surgery but had not been readmitted would have been admitted to another hospital during the study period. To investigate this issue, 450 patients of the study population were randomly selected based on the Morgan table and contacted by telephone about the possibility of their readmission in other hospitals.

Two data collection forms, created based on the literature review and verified by three experts, were used to collect patient data, readmission rates, and hospital performance indicators for 12 months. The forms collected data related to the patients' age, gender, type of insurance, place of residence, occupation, cause of admission, type of treatment, admission date, discharge date, length of stay, reason for readmission, and readmission and discharge dates. Moreover, the forms gathered data on 5 items related to hospital performance indicators, i.e. average length of stay for patients, bed turnover rate, percentage of bed occupancy, bed turnover interval, and mortality rate. The above-mentioned items from the collection data forms, duration of the performance indicators, and readmission rates were categorized on a monthly basis over a given year.

After obtaining ethical approval for the study from Iran University of Medical Sciences, the researchers obtained permission from the related authorities and the manager of the selected teaching hospital to collect the required data. They were committed to preserving confidentiality regarding the patients' information and the name of the hospital.

Then, patients' readmissions data and the hospital performance indicators were gathered according to the data collection forms with successive visits to the statistics and medical records units of the hospital. Using the hospital information system, patients who were readmitted to the hospital during the first 90 days after heart surgery were identified. The medical records of all rehospitalization cases were studied and the relevant information collected.

Moreover, 450 patients who were not readmitted to the hospital were also identified and questioned in a telephone conversation about the possibility of their being readmitted to other hospitals.

Data was analyzed using descriptive statistics (frequency, percentage, mean, and standard deviation), Spearman correlation coefficient (because only 12 months of data was gathered), and SPSS 20.

\section{Results}

Data analysis results indicated that among the 849 patients who had undergone open heart surgery in the selected teaching hospital, a total of 106 patients (12.5\%) had been readmitted within the first 90 days after discharge, and of these cases, $84 \%$ were readmitted within 30 days after discharge.

The 450 patients who were not readmitted to the 
studied hospital were called, and it was found that 14 (approximately 3.1\%) of them had been readmitted to other hospitals within 90 days after discharge. As shown in Table 1 , most readmitted patients were women (55.7\%), living in rural areas (59.4\%), and mostly housekeepers (49.1\%). The average age of the readmitted patients was 64.5 years, and their average length of stay (LOS) was 21.65 days.

As seen in Table 2, the most common reason for patient readmission was coronary artery disease (CAD) (49.1\%), and the highest frequency of their treatment type was coronary artery bypass grafting (CABG) (49.1\%).

It should be noted that 106 patients were readmitted to the hospital with the first 90 days after heart surgery (Table 2), while 6 of them were readmitted 2 times after heart surgery. Therefore, the total number of readmissions was 112 times (Table 1 ).

Table 1. Demographic Characteristics of Readmitted Patients, September 2015-2016

\begin{tabular}{|c|c|c|c|}
\hline Variable & Type & No. & $\%$ \\
\hline \multirow{2}{*}{ Gender } & Male & 47 & 44.3 \\
\hline & Female & 59 & 55.7 \\
\hline \multirow{4}{*}{ Age } & $>50$ & 8 & 7.5 \\
\hline & $50-59$ & 28 & 26.4 \\
\hline & $60-69$ & 37 & 34.9 \\
\hline & $>70$ & 33 & 31.1 \\
\hline \multirow{2}{*}{$\begin{array}{l}\text { Place of } \\
\text { habitation }\end{array}$} & Rural & 63 & 59.4 \\
\hline & Urban & 43 & 40.6 \\
\hline \multirow{5}{*}{ Occupation } & Housekeeper & 52 & 49.1 \\
\hline & Self-employed & 34 & 32.1 \\
\hline & Farmer & 11 & 10.4 \\
\hline & Retired & 6 & 5.7 \\
\hline & Employee & 3 & 2.8 \\
\hline \multirow{5}{*}{$\begin{array}{l}\text { Length of stay } \\
\text { (LOS) (day) }\end{array}$} & $<10$ days & 14 & 13.2 \\
\hline & $10-14$ & 15 & 14.2 \\
\hline & $15-21$ & 41 & 38.7 \\
\hline & $22-29$ & 16 & 15.1 \\
\hline & $\geq 30$ & 20 & 18.9 \\
\hline \multirow{4}{*}{$\begin{array}{l}\text { Cause of } \\
\text { hospitalization }\end{array}$} & CAD & 52 & 49.1 \\
\hline & MR & 6 & 5.7 \\
\hline & $C A D \& M R$ & 38 & 35.8 \\
\hline & Others & 10 & 9.4 \\
\hline \multirow{6}{*}{$\begin{array}{l}\text { Type of } \\
\text { treatment }\end{array}$} & CABG & 52 & 49.1 \\
\hline & Mitral valve repair & 4 & 3.8 \\
\hline & Replacing mitral valve & 3 & 2.8 \\
\hline & $\begin{array}{l}\text { CABG \& mitral valve } \\
\text { repair }\end{array}$ & 34 & 32.1 \\
\hline & $\begin{array}{l}\text { CABG \& replacing mitral } \\
\text { valve }\end{array}$ & 5 & 4.7 \\
\hline & Others & 8 & 7.5 \\
\hline \multicolumn{2}{|c|}{ Total patients readmitted } & 106 & 100 \\
\hline
\end{tabular}

Table 3 shows the monthly status of patient readmissions and performance indicators, including bed occupancy rate, number of deaths, LOS, bed turnover rate, and bed turnover interval in the selected teaching hospital in northern Iran from mid-September 2015 to 2016 (Table 3).

According to the results of the Spearman correlation coefficient test (Table 4), bed turnover rate and readmissions had a reverse statistically significant correlation $(P=0.018)$. Also, bed occupancy rate and readmissions had a reverse statistically significant correlation $(P=0.042)$. This indicates that increasing bed turnover and bed occupancy rates will decrease patient readmission rate (Table 4).

It is necessary to note that the result of the Spearman correlation coefficient test on the collected data indicates that there is no significant statistical correlation between patient readmissions and other performance indicators, including length of stay $(P=0.175)$, bed turnover interval $(P=0.119)$, and mortality $(P=0.399)$ (Table 4$)$.

\section{Discussion}

Based on the collected data, the findings indicate that among the 849 patients who had undergone open heart surgery in the selected teaching hospital in northern Iran, a total of 106 of them (12.5\%) were readmitted within 90 days, and among them, $84 \%$ were readmitted within 30 days after discharge. Also, it was estimated that 3.1\% of the patients were readmitted to other hospitals during this 90 -day period. The most common reason for patient readmission was $\mathrm{CAD}(49.1 \%)$, and the treatment type with the highest frequency was CABG (49.1\%).

The most important reasons for readmission in this study were infection in surgery site $(25.8 \%)$, pleural effusion (18.7\%), Warfarin toxicity (9.8\%), and tamponade (8.9\%).

Table 2. Reasons for Patient Readmission After Heart in September 2015-2016

\begin{tabular}{lcc}
\hline Reason for readmission & No. & \% \\
\hline Infection in surgery place & 29 & 25.8 \\
Pleural effusion & 21 & 18.7 \\
Warfarin toxicity & 11 & 9.8 \\
\hline Stroke & 7 & 6.2 \\
\hline Tamponade & 10 & 8.9 \\
Arrhythmia & 4 & 3.5 \\
Shortness of breath & 4 & 3.5 \\
Chest pain & 3 & 2.7 \\
Pneumonia & 4 & 3.5 \\
Sepsis & 2 & 1.9 \\
Headache and dizziness & 2 & 1.9 \\
\hline Anemia & 2 & 1.9 \\
Congestive heart failure & 3 & 2.7 \\
\hline Heart failure & 2 & 1.9 \\
\hline Irrelevant reasons & 8 & 7.1 \\
\hline Total number of readmissions & 112 & 100 \\
\hline
\end{tabular}


There were inverse relationships between readmissions and the two performance indicators of bed occupancy percentage $(r=-0.594, P=0.042)$ and bed turnover rate ( $\mathrm{r}=-0.664, P=0.018$ ), and there were no statistically significant correlations between any of the other indicators (length of stay, mortality, and bed turnover interval) and patient readmission $(P>0.1)$.

Espinoza et $\mathrm{al}^{23}$ estimated the rate of rehospitalization 30 days after open heart surgery to be $11.7 \%$, average patient age was 65 , and most readmitted patients were women with a length of stay of more than five days. The highest rate of surgery was related to $\mathrm{CABG}$, which was consistent with the present study.

Iribarne et $\mathrm{al}^{18}$ showed that the rate of rehospitalization 65 days after open heart surgery was $18.7 \%$, of which $80.6 \%$ comprised readmissions within 30 days after surgery. The main reasons for readmission included infection, arrhythmia, increased intravascular volume, pleural effusion, and chest pain. The average length of stay was 22 days and rehospitalization occurred most among females and CABG patients. The average age of readmitted patients was 64 years.

The findings of the present study are relatively consistent with those of Iribarne et al, except for the rehospitalization rate. The high readmission rate seen in the study of Iribarne et a ${ }^{18}$ compared with that of the present study could be due to their larger sample size and greater number of centers. ${ }^{10}$

Redzek et $\mathrm{al}^{9}$ determined the rate of readmission among open heart surgery patients to be $9.54 \%$, of which $56.2 \%$ were readmitted within 30 days after surgery. Congestive heart failure, sternal dehiscence, arrhythmia, infection, chest pain, and pericardial effusion were the most important reasons for readmission. The average age of the readmitted patients was 68 years, and CABG was the most common cause of heart surgery, which is consistent with the findings of the present study.

Magnus et $\mathrm{al}^{24}$ found that the most important causes for readmission in patients with open heart surgery were infection, tamponade, pleural effusion, and arrhythmia, which seems comparable with the findings of the present study.

Redzek et $\mathrm{al}^{9}$ concluded that there was no significant correlation between length of stay and readmission after open heart surgery, which is consistent with the findings of the present study.

Sud et $\mathrm{al}^{25}$ conducted a cohort study on 58,230 patients suffering from heart failure in Canada. Their results showed that a long length of stay is correlated with increases in readmission and mortality. The present study did not show a meaningful relationship between length of stay and readmission, although this correlation was negative. Compared with the findings of Sud et $\mathrm{al},{ }^{25}$ it is possible to assume that different results would have been obtained if the present study period lasted longer than one year and more hospitals were studied.

Maniar et $\mathrm{a}^{26}$ concluded that there was a positive correlation between length of stay and readmission in open heart surgery patients; increasing the length of stay may result in increasing readmissions. The difference between the results of the present study and those of Maniar et $\mathrm{al}^{26}$ could be due to their use of a logistic regression model, a high number of samples (2096), and a longer period (25 months).

Lingsma et al studied patients discharged from 26 hospitals during 2007 to 2012. Their findings revealed that the readmission rate among these patients was not associated with either long length of stay or mortality. According to the findings of the current study, there was no significant correlation between readmission and the two indicators of mortality and LOS, which confirms the study results of Lingsma et al. ${ }^{21}$

Do et $\mathrm{al}^{27}$ studied the effect of a heart failure care program on the outcomes of 257 patients in Vietnam. Their results revealed that the readmission rate 60 days after discharge

Table 3. Monthly Status of Readmissions and Performance Indicators of the Hospital Under Study During Mid-September 2015-2016

\begin{tabular}{|c|c|c|c|c|c|c|}
\hline Month & No. of Readmissions & Bed Occupancy (\%) & No. of Mortality & Length of Stay (LOS) & Bed Turnover Rate & Bed Turnover Interval \\
\hline 1 & 7 & 93 & 0 & 4.9 & 27.9 & 4.7 \\
\hline 2 & 13 & 86.7 & 2 & 6 & 26 & 5.7 \\
\hline 3 & 11 & 82.1 & 4 & 4.5 & 24.6 & 4.3 \\
\hline 4 & 7 & 98.6 & 1 & 3.3 & 29.6 & 3.2 \\
\hline 5 & 6 & 89.4 & 8 & 6.1 & 26.8 & 5.9 \\
\hline 6 & 11 & 81.8 & 4 & 5.3 & 23.7 & 5.1 \\
\hline 7 & 15 & 49.9 & 4 & 4.5 & 15.5 & 4.2 \\
\hline 8 & 6 & 95.1 & 6 & 6 & 29.7 & 5.8 \\
\hline 9 & 10 & 93.3 & 3 & 6 & 28.9 & 5.8 \\
\hline 10 & 12 & 90 & 5 & 5.7 & 27.6 & 5.5 \\
\hline 11 & 6 & 90.2 & 6 & 6.3 & 28 & 6 \\
\hline 12 & 8 & 80.1 & 3 & 5.6 & 24.8 & 5.4 \\
\hline Total & 112 & 85.85 & 46 & 5.35 & 26.1 & 5.1 \\
\hline
\end{tabular}


Table 4. Correlation Between Performance Indicators and Readmissions in the Hospital Under Study

\begin{tabular}{|c|c|c|c|c|c|c|}
\hline Readmissions & Indicators & Min. & Max. & Mean & SD & The Result of Spearman Correlation Test \\
\hline \multirow{5}{*}{$\begin{array}{c}\text { Min. }=6 \\
\text { Max. }=15 \\
\text { Mean }=9.33 \\
\text { SD }=3.08\end{array}$} & Bed turnover rate & 15.5 & 29.7 & 26.09 & 3.86 & $\mathrm{r}=-0.664, P=0.018$ \\
\hline & Bed occupancy rate & 49.9 & 98.6 & 85.85 & 12.64 & $r=-0.594, P=0.042$ \\
\hline & Bed turnover interval & 3.2 & 6 & 5.13 & 0.86 & $r=-0.474, P=0.119$ \\
\hline & Length of stay (LOS) & 3.3 & 6.3 & 5.35 & 0.89 & $r=-0.419, P=0.175$ \\
\hline & Mortality & 0 & 6.1 & 2.8 & 1.73 & $r=-0.269, P=0.399$ \\
\hline
\end{tabular}

was $12.5 \%$, which is similar to the readmission rate within 90 days after discharge in the present study.

Parker et $\mathrm{al}^{28}$ conducted a cohort study with 162 patients aged 18 years who had undergone cardiac surgery between 2010 and 2014. They found that $12.9 \%$ of the patients experienced readmission or death during the first 30 days after discharge. This finding matches that of the present study, although the average age of the patients differed between the two studies. Parker et al also showed a correlation between readmission and mortality after surgery, which is not comparable with this study, possibly because of the different methodologies, study periods, and the average age of the samples.

The rate of readmission, reasons for it, and its relationship with some performance indicators may be confirmed by other research results, although in some cases the evidence does not support the findings of this study.

As a limitation of this study, it should be mentioned that among the various performance indicators of hospitals, only five were selected and investigated in this study. It seems that more, other hospitals should be studied.

\section{Conclusion}

This study indicated that the most important reasons for readmission after cardiac surgery in the teaching hospital include infection, pleural effusion, warfarin toxicity, and tamponade. Patient readmission was found to be inversely correlated with bed occupancy and bed turnover rate. The hospital administrators may use these results in planning for proper bed management and targeting interventions to reduce costs and decrease patients' readmissions after cardiac surgery. The main causes and related factors of patient readmission identified in this study can give a better understanding so as to take advantage of hospital data and performance indicators in line with increasing efficiency and effectiveness.

According to the results of this study and other similar studies, infection is one of the most important causes of readmission, which also requires the adoption of necessary measures and initiatives to moderate and reduce the rate of readmission of patients after open heart surgery and, ultimately, to improve the quality of service.

\section{Authors' Contributions}

PE, MTNDN, SV, and GFG designed the study. PE and MTNDN supported all steps of the study. Literature review and gathering data was done by MTNDN. All the authors contributed to the analysis and interpretation of data. PE and MTNDN wrote, translated, and revised the paper.

\section{Conflict of Interest Disclosures}

There was no conflict of interest in this study.

\section{Ethical Approval}

Due to ethical considerations, the confidentiality of the collected data was preserved at various stages of this research. The current study was approved by the Ethics Committee of the Vice-Chancellor for Research and Technology of Iran University of Medical Sciences with code No. IR.IUMS.REC.1395.9211564205.

\section{Acknowledgments}

This article is based on a master's thesis titled "The relationship between performance indicators and readmissions of patients with open heart surgery in the teaching hospital: 2015-2016", sponsored by the Vice-Chancellor for Research and Technology of Iran University of Medical Sciences with the code IUMS/ SHMIS_1395/9211564205. The current researchers are extremely grateful to the honorable authorities of Iran University of Medical Sciences and the teaching hospital for their support of this research as well as all those who provided us with their experiences.

\section{Research Highlights}

\section{What Is Already Known?}

Cardiac surgery is among the major and vital treatments of patients suffering from cardiovascular diseases. One of the undesirable effects of heart surgery is patient readmission, which its decline may result in the improvement of healthcare quality and may also decrease costs.

\section{What This Study Adds?}

Patient readmission following heart surgery is correlated with performance indicators including bed occupancy and bed turnover rates. Considering the extent, reasons and the correlated variables, patient readmission can be used for better management of hospital beds and implementing targeted interventions to reduce readmission rate in order to improve quality and efficiency. 


\section{References}

1. Roth GA, Johnson C, Abajobir A, et al. Global, regional, and national burden of cardiovascular diseases for 10 causes, 1990 to 2015. J Am Coll Cardiol. 2017;70(1):1-25. doi:10.1016/j. jacc.2017.04.052.

2. Min YI, Anugu P, Butler KR, et al. Cardiovascular disease burden and socioeconomic correlates: findings from the Jackson Heart Study. J Am Heart Assoc. 2017;6(8). doi:10.1161/ jaha.116.004416.

3. Targonska-Stepniak B, Biskup M, Biskup W, Majdan M. Gender Differences in Cardiovascular Risk Profile in Rheumatoid Arthritis Patients with Low Disease Activity. Biomed Res Int. 2019;2019:3265847. doi:10.1155/2019/3265847.

4. Raghfar H, Sargazi N, Mehraban S, Akbarzadeh MA, Vaez Mahdavi MR, Vahdati Manesh Z. The Economic Burden of Coronary Heart Disease in Iran: A Bottom-up Approach in 2014. Journal of Ardabil University of Medical Sciences. 2018;18(3):341-356. doi:10.29252/jarums.18.3.341. [Persian].

5. Gharasi-Manshadi M, Meskarpour-Amiri M, Mehdizadeh P. Lost productivity among military personnel with cardiovascular disease. J R Army Med Corps. 2018;164(4):235-239. doi:10.1136/jramc-2018-000920.

6. Bartel T, Rivard A, Jimenez A, Mestres CA, Muller S. Medical three-dimensional printing opens up new opportunities in cardiology and cardiac surgery. Eur Heart J. 2018;39(15):12461254. doi:10.1093/eurheartj/ehx016.

7. Afilalo J, Kim S, O'Brien S, et al. Gait speed and operative mortality in older adults following cardiac surgery. JAMA Cardiol. 2016;1(3):314-321. doi:10.1001/jamacardio.2016.0316.

8. Hosseini M, Ramazani J. The predictors of morbidities after cardiac surgery. Journal of Iranian Society of Anesthesiology and Critical Care. 2013;35(82). [Persian].

9. Redzek A, Mironicki M, Grozdenovic A, et al. Predictors for hospital readmission after cardiac surgery. J Card Surg. 2015;30(1):1-6. doi:10.1111/jocs.12441.

10. Borregaard B, Dahl JS, Riber LPS, et al. Effect of early, individualised and intensified follow-up after open heart valve surgery on unplanned cardiac hospital readmissions and allcause mortality. Int J Cardiol. 2019;289:30-36. doi:10.1016/j. ijcard.2019.02.056.

11. Greco G, Shi W, Michler RE, et al. Costs associated with health care-associated infections in cardiac surgery. J Am Coll Cardiol. 2015;65(1):15-23.doi:10.1016/j.jacc.2014.09.079.

12. Shih T, Dimick JB. Reliability of readmission rates as a hospital quality measure in cardiac surgery. Ann Thorac Surg. 2014;97(4):1214-1218. doi:10.1016/j.athoracsur.2013.11.048.

13. Wang $\mathrm{H}$, Robinson RD, Johnson $\mathrm{C}$, et al. Using the LACE index to predict hospital readmissions in congestive heart failure patients. BMC Cardiovasc Disord. 2014;14:97. doi:10.1186/1471-2261-14-97.

14. Donze JD, Williams MV, Robinson EJ, et al. International validity of the HOSPITAL score to predict 30-day potentially avoidable hospital readmissions. JAMA Intern Med. 2016;176(4):496502. doi:10.1001/jamainternmed.2015.8462.

15. Honeyford K, Aylin P, Bottle A. Should Emergency Department Attendances be Used With or Instead of Readmission Rates as a
Performance Metric?: Comparison of Statistical Properties Using National Data. Med Care. 2019;57(1):e1-e8. doi:10.1097/ mlr.0000000000000899.

16. Hoyer EH, Padula WV, Brotman DJ, et al. Patterns of Hospital Performance on the Hospital-Wide 30-Day Readmission Metric: Is the Playing Field Level? J Gen Intern Med. 2018;33(1):57-64. doi:10.1007/s11606-017-4193-9.

17. Gilstrap LG, Joynt KE. Understanding the relationship between readmission and quality of hospital care in heart failure. Curr Heart Fail Rep. 2014;11(4):347-353. doi:10.1007/s11897-0140209-5.

18. Iribarne A, Chang $\mathrm{H}$, Alexander $\mathrm{JH}$, et al. Readmissions after cardiac surgery: experience of the National Institutes of Health/ Canadian Institutes of Health research cardiothoracic surgical trials network. Ann Thorac Surg. 2014;98(4):1274-1280. doi:10.1016/j.athoracsur.2014.06.059.

19. Mirzaeyan S, Izadi AR, Ebrazeh A, Mohammadi P. Prediction of readmission based on LACE index in medical ward of Hajar hospital of Shahrekord. Journal of Clinical Nursing and Midwifery. 2014;3(2):1-12. [Persian].

20. Blom MC, Erwander K, Gustafsson L, Landin-Olsson M, Jonsson $\mathrm{F}$, Ivarsson $\mathrm{K}$. The probability of readmission within 30 days of hospital discharge is positively associated with inpatient bed occupancy at discharge--a retrospective cohort study. BMC Emerg Med. 2015;15:37. doi:10.1186/s12873-015-0067-9.

21. Lingsma HF, Bottle A, Middleton S, Kievit J, Steyerberg EW, Marang-van de Mheen PJ. Evaluation of hospital outcomes: the relation between length-of-stay, readmission, and mortality in a large international administrative database. BMC Health Serv Res. 2018;18(1):116. doi:10.1186/s12913-018-2916-1.

22. Rao A, Kim D, Darzi A, Majeed A, Aylin P, Bottle A. Regional variations in trajectories of long-term readmission rates among patients in England with heart failure. BMC Cardiovasc Disord. 2019;19(1):86. doi:10.1186/s12872-019-1057-8.

23. Espinoza J, Camporrontondo $M$, Vrancic $M$, et al. 30-day readmission score after cardiac surgery. Clin Trials Regul Sci Cardiol. 2016;20:1-5. doi:10.1016/j.ctrsc.2016.05.006.

24. Magnus PC, Chaisson K, Kramer RS, et al. Causes of 30-day readmission after cardiac surgery in Northern New England. J Am Heart Assoc. 2011;124(21):A13474.

25. Sud M, Yu B, Wijeysundera HC, et al. Associations between short or long length of stay and 30-day readmission and mortality in hospitalized patients with heart failure. JACC Heart Fail. 2017;5(8):578-588. doi:10.1016/j.jchf.2017.03.012.

26. Maniar HS, Bell JM, Moon MR, et al. Prospective evaluation of patients readmitted after cardiac surgery: analysis of outcomes and identification of risk factors. J Thorac Cardiovasc Surg. 2014;147(3):1013-1018. doi:10.1016/j.jtcvs.2013.10.066.

27. Do TNP, Do QH, Cowie MR, et al. Effect of the Optimize Heart Failure Care Program on clinical and patient outcomes - The pilot implementation in Vietnam. Int J Cardiol Heart Vasc. 2019;22:169-173. doi:10.1016/j.ijcha.2019.02.010.

28. Parker DM, Everett AD, Stabler ME, et al. Biomarkers associated with 30-day readmission and mortality after pediatric congenital heart surgery. J Card Surg. 2019;34(5):329-336. doi:10.1111/jocs. 14038 . 